\title{
SUSTAINABLE DESIGN APPROACHES USING WASTE FURNITURE MATERIALS FOR DESIGN STUDENTS
}

\author{
Sua LEE and Lyndon BUCK \\ Buckinghamshire New University, United Kingdom
}

\begin{abstract}
Sustainability has become one of the core concerns of current designers and makers. However, it is still evident that not every designer considers a choice of sustainable materials, manufacturing methods, afterlife or second use of their designs for furniture and other products unless the client, brief, customer or user demands it. The lack of established research for practice-based design practice with waste materials for designers has led to the development of a naturalistic approach within this work which is both craft-based and commercially focused. The central aim of the study is to explore how designs are sustainably approached in the commercial context of young product design companies in the UK, and to propose a set of practical guidance through design outcomes to help design students deal with environmental issues via design and waste material reuse. This research functions as an articulation of a research journey that provides a discursive platform for dialogue and review, facilitating new insights into a creative practice that contributes to new knowledge by efficiently crafting objects in a commercial context using discarded materials. This then shows that this form of waste can be adaptable and practicable as the main material for upcycling into commercial products in repeatable batch production runs. As a result, a product collection was produced to help gain a practised understanding of reusing elements of furniture waste as a primary material source and make creative connections through a structured process of reflection and discussion on practice. This work may inspire designers and students to reconsider the use of waste materials in their practice, to rediscover the beauty and usefulness of these materials, and through a structured design process using the guidelines make attractive commercial products, raise awareness of material reuse, and help to make a net positive environmental impact.
\end{abstract}

Keywords: Sustainable design, design education, product design, material reuse, design pedagogy

\section{INTRODUCTION}

We are living in a world surrounded by waste, no matter how hard we try to reduce, reuse, and recycle, or how often we see waste mountains on the land and in the sea. This has provoked many designers to consider how we can solve this global environmental issue. New definitions of good product design should include environmental considerations [1], but what if we, as designers, are producing more waste and encouraging consumption in the name of sustainable, eco, green, or zero waste design?

Design for the Real World by Papanek [2] argues that the designer's responsibility is not to encourage expenditure but, rather, to encourage people to make better decisions for themselves and for the places where they reside. Bhamra and Lofthouse [3] argue that designers must take further responsibility because of the role they play in the industry's connection with the marketplace, interacting between people and products. We can all see how important the designers' role is for the current environmental situation. What we do not always see is we live in a 'buy and sell' society and consumption is just part of life. We designers need to be more careful about what we are producing. The desire for new products is not going to change and consumerism will not stop, although it may start to slow over time [4]. This study has been established to seek out a solution to a current waste issue as a practitioner, designing products to respond to that issue and how this can be assigned and practised in design education.

The core aims of this research are to create alternative design processes for small design practitioners and businesses that uses waste material in a sustainable manner, to produce an environmental business framework that could encourage more young designers and students to follow this course of action by reducing the existing waste that goes to landfill, transforming waste into beautiful, marketable products 
with commercial value, and thereby encouraging material reuse and reconsideration. There have been many diverse environmentally considered design approaches before, such as using various recycled materials, the development of sustainable materials, and the reduction of energy consumption, yet, reusing the waste which remains after production has seemingly been often ignored or little investigated as a raw material, especially furniture waste. This study focuses to the need to raise the awareness of waste furniture material as the main media to be (re)used to increase is value and reduce prejudice against it by buyers. Three main texts, Thinking Through Craft [5] (Adamson, 2007), The Craftsman [6] (Sennett, 2008) and The Shape of Green [7] (Hosey, 2012) have been used to support the reason for the design decision-making during the development of the products for design practice.

This paper is divided into two sections. The first explores examples of sustainable design in the past and present to support learning through approaches to evaluation and develops them into practical experiments through a contextual and theoretical exploration and literature review. It describes the data collection process through a collaboration with a student design project reusing waste materials to find the possibility, necessity and feasibility of waste reusing products in the market. The second section involves carrying out field research in the furniture and product design industry to discuss the notion of design practice in businesses considering employing design graduates, and moves on to evaluation through personal practical-based application to find adaptable alternate design approaches for learning in an educational context and encouraging young entrepreneurs in the sustainable design sector.

\section{SUSTAINABLE DESIGN EXAMPLES FROM THE PAST AND THE PRESENT}

Nowadays, there are diverse environmentally considered design approaches, such as using recycled materials, the development of sustainable materials, and the reduction of energy consumption. Designers are embracing their work through new forms of sustainable materials such as 'Mycelium + Timber' (Figure 1) and 'Newspaper Wood' (Figure 2) or focusing on the reduction of energy consumption in an innovative way, such as by building furniture pieces using the packaging itself (Figure 3 ) and growing trees into furniture shapes (Figure 4) to be environmentally friendly.

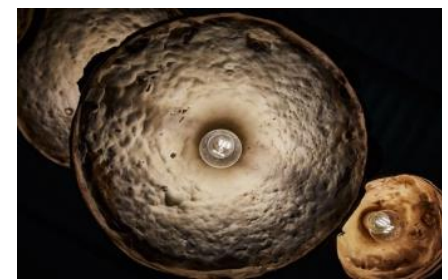

Figure 1. Mycelium light

by Sebastian Cox and Ninela Ivanova, 2017

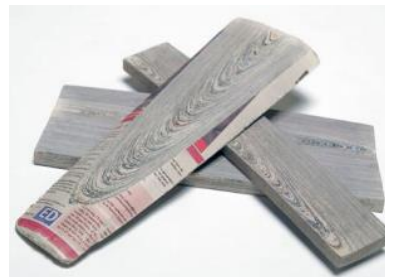

Figure 2. 'Newspaper Wood' by Vij5, 2011

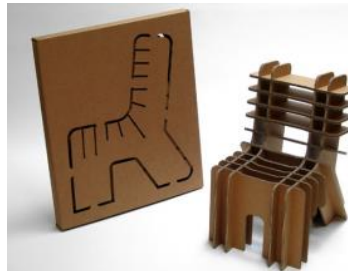

Figure 3. FIY chair by David Graas, 2007

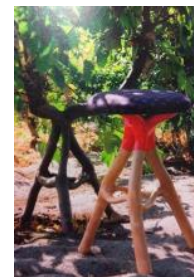

Figure 4. Grown-up furniture stool, Chris Cattle, 2002

Despite the efforts of these designs, waste remains a huge concern for the environment. Thus, this study investigates past designs to see if there are design inspiration that can be transferred to the present day. In the past, green or sustainable design has been touched on, particularly in post-war design, which often reflects the feelings and character of the era; this was out of necessity due to material and labour shortages rather than an awareness of environmental issues. In Ting Tang Trash, art historian Jorunn Veiteberg [8] said in regard to ceramics that post-industrial trends stood out relevantly in the 2000s as a completely new trend in craft, though not new in a way that represented a break with the past. 'The past is present everywhere', and through this review of history, furniture was given an important aspect regarding the choice of materials and motifs as well as work methods and themes. The similarities and common threads running through modern sustainable design, Postmodernism, Adhocism, Utility Furniture, and Make-do and Mend, including the use of reduced and reused materials in products. For example, during World War II, when 'make do and mend' was suggested, resources were limited, and the public were forced to restrict the use of furniture. Utility furniture was developed and produced to provide fully functioning furniture of sound construction with an agreeable design and reasonable price. As such, Utility furniture has become its own style by reducing the decorative articles of design, using simple designs with straight lines that reduce the use of raw materials and minimise waste during production. This is like eco-design in contemporary products, where designs are primarily developed to preserve the environment. In addition, 'make do and mend' arose from the need to be resourceful during 
material shortage during and after war. As it was used for economic advantage, it created the concept of reusing materials in an inventive way by altering them to repair and patch. This gave shows that new ways of applying old materials can create a unique style, such as Réanim by 5.5 Designers (Figure 5) where the idea gives a new lease of life for damaged furniture. As the restrictions of the time influenced the design of the era by developing mending skills, Postmodernism and Adhocism were discussed for their attitudes to design, which resulted in the approach of contemporary sustainable design. Finding new uses for material to create alternate functions from its original purpose, such as Esther Coombs' cake stand (Figure 6) with her own illustration that is not just using chipped mugs as plant pots, but creating a piece in a more considered, creative and imaginative way and Martino Gamper's ' 100 chairs in 100 days' (Figure 7) which reassembled used discarded and damaged chairs into poetic forms. The project was about being creative, but within restrictions [9], using improvised objects to create unexpected positive results by transforming limitations into 'elements of possibility'. As this approach uses existing materials, a designer's craft, viewpoint and understanding of materials become unique points of their products, which has been the focus of this design practice.

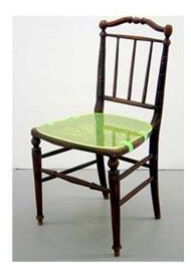

Figure 5. Prosthetic chair seat by 5.5 design studio

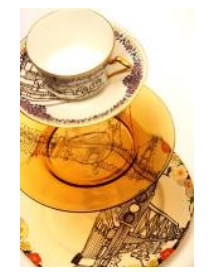

Figure 6. Cake stand by Esther Coombs

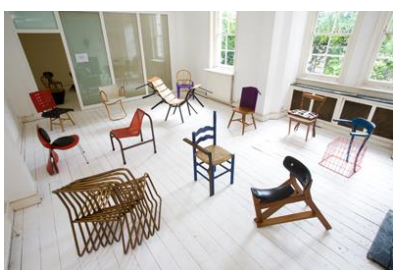

Figure 7. '100 chairs in 100 days' by Martino Gamper

\subsection{Design project collaboration with students using waste and public perception}

After the inspirational findings from past designs, as a craftsperson and designer-maker, knowing consumer's shifting opinions on making products from waste and maintaining knowledge of products in the market is crucial for encouraging students, especially those who are interested in future design employment. To get an idea of the market and user needs and opinions on the products, waste materials, and to detect potential markets, a survey was conducted through a project with MA Art and Design students from Bucks New University. The survey was conducted via an exhibition in London showrooms (Figure 8,9) at which the object's appeal caught the public's attention to illustrate the possibilities and encourage participation. A survey was designed to gauge the public's perception of waste and products made using waste materials, and it was carried out over five years in three different venues between 2012 and 2017. The reason for designing this survey method for delivery through the exhibition was to encourage participation by attracting, contextualising, and inspiring using threedimensional objects rather than simply asking participants to read and answer the paper questionnaire. The project asked the students to imagine that they were Charles and Ray Eames and to produce a model of a functional design, made primarily of, or be inspired by, waste. The designs were displayed on a plinth with a white board for the public to assign a score and rationale for their favourite work. In the demonstration sites, which included commercial furniture and product showrooms, trade fairs and exhibitions, questionnaire sheets were provided to interrogate a trading and market rationale and a willingness to purchase products made using discarded materials at a commercially realistic retail price.

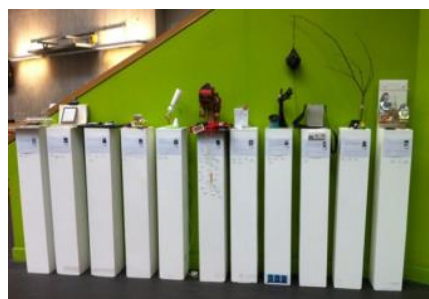

Figure 8. Beautiful Waste-products designed by Bucks New MA students

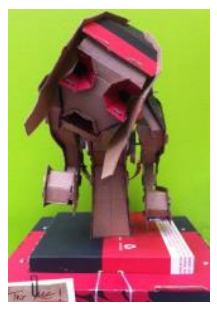

Figure 9. Help me find Margherita by MA student Kamal Wasala 
According to Postrel [10], aesthetics is not a luxury, but a universal human desire, and data collected from the project has shown that people purchase goods because of perceived innovations within the design. A noteworthy outcome from the data collection is that the public's choice of favourite designs in the exhibition is not because of their 'green-ism', but because of their creativeness - their 'design value'. As the products are physically presented and viewed, people are captivated by their appearance and when they discover the backstory of using waste materials, they become more interested in the environmental considerations. This shows that however compelling the environmental backstory of a product, it is still of utmost importance that it has appeal on an aesthetic and functional level.

\subsection{Case studies in small design businesses using waste materials}

This study investigates how young contemporary furniture design companies in the UK employ environmentally friendly manufacturing to seek appropriate strategies that could be applicable to student design practices in education. Five UK designers and design studios who use waste materials mainly for their products - DZ Design, Hendzel+Hunt, Furniture Magpies, Jay \& Co., and Geoffrey Fisher - were interviewed. All five designers had difficulties at the beginning with aspects such as time management and finances and are still currently learning about methods of promotion, target markets, trading channels, routes of business expansion, channels and sources of funding, and future visions for business growth. The most common problem among the design entities is a lack of resources such as finances, time, workforce, and materials, all of which are closely linked to the smooth running of a business.

The most common hindrance of working with and using waste materials are the demands of longer processing time, and the difficulty in repeating the product due to limitations with discarded objects on the ground as they are restricted in size, quality, and quantity. Therefore, it is wise to employ less time in production and reducing time on production can be done either by limiting the time consumed during the making process or deliberately emphasising one part of the entire piece so it stands out. Geoffrey Fisher [11] affirms that limiting the design development period to no more than two weeks is vital for work efficiency; the product development period is the first step, and the next steps, such as seeking and receiving feedback for improvements, pricing, dealing with retailers, making, packing, and delivery need to be achieved quickly. This entails designers' craftsmanship, creative thinking, and making skills. All five businesses commented that little things that are easy to miss during product development should be deeply considered; public opinions must also be embraced. Another action to consider when generating an item is that there should be a continuous supply for repeating orders. For example, then, the making method is simple and duplicable using easily accessible materials. If any young entrepreneurs are interested in opening their own studio like the case studies, efficiency in every step is core to making a business successful which can be one of the points to focus while in teaching students.

\subsection{Author's design practice and application of research findings}

Inspired by the findings from the contextual history review (e.g. do not be biased by environmental priority in design but maintain various perspectives on the design approach) and the case studies (e.g. be both craft-minded and business-minded), five designs were developed: FM Coatrack (Figure 10); Stuck Door Wedge (Figure 11); Build Up Lamp (Figure 12); Ad-hoc Candelabra (Figure 13) and Arti Ring Holder (Figure 14). These products have all been developed into retail products and sold online.

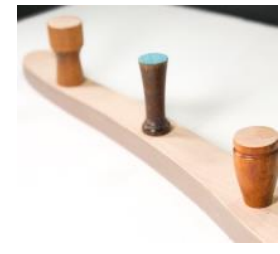

Figure 10.

FM Coat rack

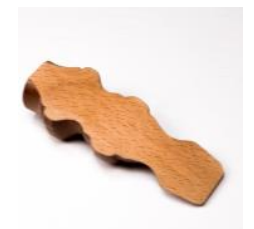

Figure 11.

Stuck Door Wedge

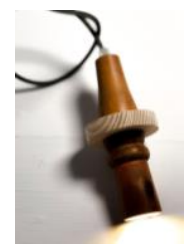

Figure 12. Build Up Lamp

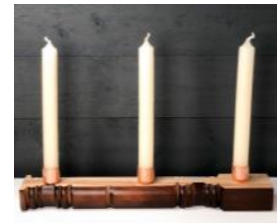

Figure 13. Ad-hoc Candelabra

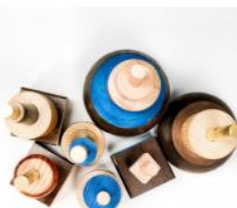

Figure 14. Arti Ring Holder

These five objects are mainly tied to traditional materials, e.g. solid wooden chairs and tables that have unique figures. This is not only because environmental concerns encompassed all aspects of the reuse but also because the impression of the products' lines attracted the designer, as this type of furniture was not popular during the designer's childhood due to cultural differences. Moreover, the reason behind the material choice is that timber is an easily accessible material found in everyday objects which could be 
a plus factor for an experiment in a limited environment. This is unlike other raw materials in board or plank form as it has idiosyncratic features that depend on the form and function of the furniture. This practice was a testament to the strength, value, and enduring nature of the furniture and the repurposing liveliness of its original form to a new role as a designer. It is an endless personal journey toward the ideal or desired self that, by its very nature, becomes a process of incremental destruction [12]. What this research found throughout its practical experiment stage (especially with the furniture waste materials during the design improvisation) is that a successful business is possible if products apply discoveries from MA projects and case studies. Decreasing production time by increasing the material compatibility between products with a clever design and aesthetic appearance within an acceptable market price is the key. The idea of completely rethinking, deconstructing, and reworking pre-owned furniture served to substantialise the design aesthetic and brought the validity of the materials to light. Creating a standard for the measurement and production processes of the waste materials using the right tools is indispensable for increasing the production amount. Hence, a lot of energy and time can be saved during the preparation aspect of production by dividing per process instead of starting and finishing each item individually. This may sound no different than contemporary manufacture nowadays, wherein the labour is divided to increase efficiency. However, this is a practice that has proven that the use of waste materials is applicable with an efficient process despite the difficulty of repeating the products due to the limitations of discarded objects, which has probably been the reason for the absence of products using waste materials. Thus, the practical result of this study has espoused the aspects of it and developed with concentrating efficiency as a commodity, but with agreeable design appearance.

\section{CONCLUSIONS}

From the author's personal perspective, design is future-oriented and past-inspired, so comprehending the events of the present and reflecting them in design properly is imperative [13]. Using fewer or recycled materials during production still inevitably creates rubbish, which means that waste will never be extinct. Where does the responsibility lie, and how can we ameliorate the effect on future generations? Consumers have grown accustomed to having not only what they need but also what they want [14]. As such, when we buy and use things, we all need to take more responsibility for how our actions affect the environment. Regarding the necessity and willingness to purchase waste material using products, $90 \%$ of people answered positively through survey. A designer's job is also to guide consumers in the right direction in terms of consumerism. Design is often about understanding culture and context before we even know where to start with an idea [15]. Once designers understand the real concerns of environmental issues, they will be able to lead other designers and consumers into effective action. The aim of this research was to develop a model which can provide practical advice to help young designers deal with environmental issues via design and materials reuse. Through the research, the common advantages and disadvantages in the design using waste materials have been cited, but product development using abandoned surroundings have shown the opportunity for trading like any other business. For example, the materials suggest new functions with their form and making starts by dividing the original form into smaller pieces to be ready as raw materials. Design decisions are made around the materiality, functionality and repeatability, and consideration of the knowledge of consumers' wants and needs (such as not seeing the negative connotations of waste) without losing creativity and innovation (to show the positives of the waste materials). Regarding designing and creating with furniture waste through creative thinking and with commercial validity, this study suggested a model of practice, briefly introducing it to make the process clear to practitioners: 

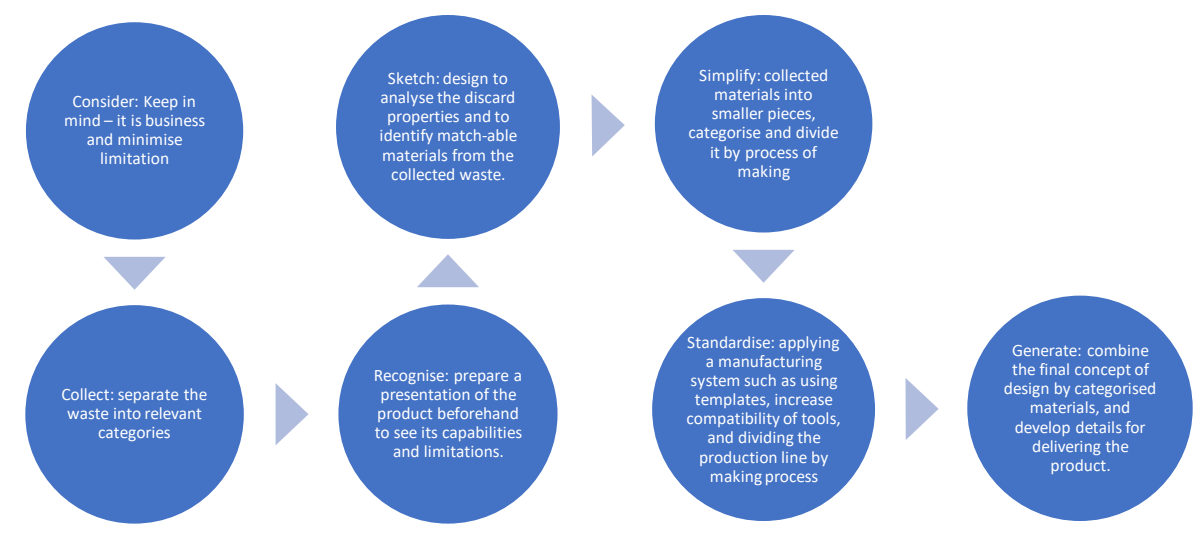

Figure 15. Model of designing and creating with furniture waste through creative thinking

This study functions as an articulation of new insights into creative practice in a commercial context using discarded materials and contributes to design education where needs the change of conception reflecting the issue of present. This way of the approaching projects within a limited environment in design education helps students to understand what the limitations on design and designer are and will improve their capability where they are dealing with real businesses. It should also help and encourage those who wish to design, develop, produce and market their own designs in the design marketplace. The growth in importance of professional practice and sustainable, ethical business practices in art and design courses, particularly in the UK as a result of the 2017 QAA Subject Benchmark Statement in Art and Design of 2017, has left gaps in suitable business tools [16] which it is hoped this could help to fill.

\section{REFERENCES}

[1] Mackenzie, D. Green Design, 1997, pp.68 (Laurence King, London).

[2] Papanek, V. Design for the Real World, 1985 (Thames \& Hudson, London).

[3] Bhamra, T. and Lofthouse, V. Design for Sustainability: A Practical Approach, 2007, pp.37 (Gower Publishing, Aldershot).

[4] Perera, H. and Gunawardana. Modern Consumerist Culture, It's Drawbacks and Benefits, International Conference on Management and Economics ICLE, 201,4 (Ruhana University, Sri Lanka).

[5] Adamson, G. Thinking Through Craft. 2007 (Berg Publishers, Oxford).

[6] Sennett, R. The Craftsman, 2008 (Penguin, London).

[7] Hosey, L. The Shape of Green. 2012 (Island Press, Washington) .

[8] Veiteberg, J. Ting Tang Trash. Bergen, 2012 (Bergen National Academy of the Arts, Norway).

[9] Gamper, M. 100-chairs-in-100-days. Available: http://martinogamper.com/project/a-100-chairsin-a-100-days/ [Accessed on 2019, 20 September], (2017) May.

[10] Postrel, V. The Substance of Style: How the rise of aesthetic value is remaking commerce, 2003 (Harper Perennial, New York).

[11] Fisher, G. 'Products using waste material in business' [Interview by S. Lee], Personal communication 7 June 2017, Geoffrey Fisher Design Studio, High Wycombe, Buckinghamshire, UK.

[12] Chapman, J. Emotionally Durable Design, 2006, p.53 (Earthscan, London).

[13] Papanek, V. The Green Imperative: Ecology and Ethics in Design and Architecture, 1985 (Thames \& Hudson, London).

[14] Elsenberg, L. Shoptimism: Why the American consumer will keep on buying no matter what, 2013 (Free Press, New York).

[15] Brown, B. 'Urges Designers to Think Big'. Available: https://www.ted.com/talks/tim_brown_urges_designers_to_think_big [Accessed on 2019, 10 November 2019] (2009) July.

[16] Allen, J. and Rowles, S. Professional Practice: 20 Questions, 2016 (The Artists Information Company). Available: https://static.a-n.co.uk/wp-content/uploads/2016/12/Professional-practicein-art-schools.pdf. 